\title{
Norwegian scabies following topical steroid therapy
}

\author{
Roger Clayton* \\ M.B., B.S., M.R.C.P.
}

\author{
SIMON FARROW \\ M.B., B.S.
}

\section{Summary}

Following an outbreak of scabies in a hospital ward, a correct diagnosis of Norwegian scabies was made in an eczematous patient whose skin had unexpectedly deteriorated with topical potent fluorinated corticosteroid therapy.

\section{Introduction}

Reports of Norwegian or crusted scabies occurring in England are rare (Calnan, 1950). In this condition itching is not a constant symptom, burrows may not be present and the acarus may be found on the head and neck. The acarus is seen within scales and the gross hyperkeratosis may give the skin the appearance of the bark of a tree. Norwegian scabies has been reported in mental defectives (Zoon and Mali, 1949; Calnan, 1950; Maguire and Kligman, 1960), in cases of lymphoma and leukaemia (Logan, Grant and Keczkes, 1967; Walshe, 1967) and during immunosuppressive therapy (Paterson, Allen and Beveridge, 1973). It is frequently diagnosed after the onset of an epidemic (Ingram, 1951; Wells, 1952). Recently an atypical case of scabies was reported in

* Requests for reprints: Dr R. J. Clayton, Department of Dermatology, St. Mary's Hospital, Praed Street, London W2 1NY. a 3-month-old child previously treated with topical $\vec{\circ}$ fluorinated steroids (Macmillan, 1972). The following appears to be the first reported case of classical $\vec{\omega}$ Norwegian scabies occurring in a patient treated with such steroids.

\section{Case report}

A 62-year-old male patient with a long past history of endogenous eczema was admitted to hospital for treatment. He had extensive involvement being virtually erythrodermic, with much scaling from the waist down. Itching was minimal. He had been treated as an outpatient with about $50 \mathrm{~g}$ daily of $\overrightarrow{\mathrm{c}}$ $0.025 \%$ betamethasone 17 -valerate. He was treated with approximately $50 \mathrm{~g}$ clobetasol proprionate $0.05 \%$ (Dermovate) ointment daily. The condition of his skin became worse with gross hyperkeratosis generalized dusky erythema, fissures in the flexures and generalized lymph node enlargement. He was ov started on a course of oral prednisolone, but withoul improvement and he became languid and irritable. At this time two other patients in the ward presented with an irritating rash diagnosed clinically as scabies. Shortly afterwards two nurses, six further patients and the ward houseman were similarly diagnosed. The skin patient was re-examined and many acari

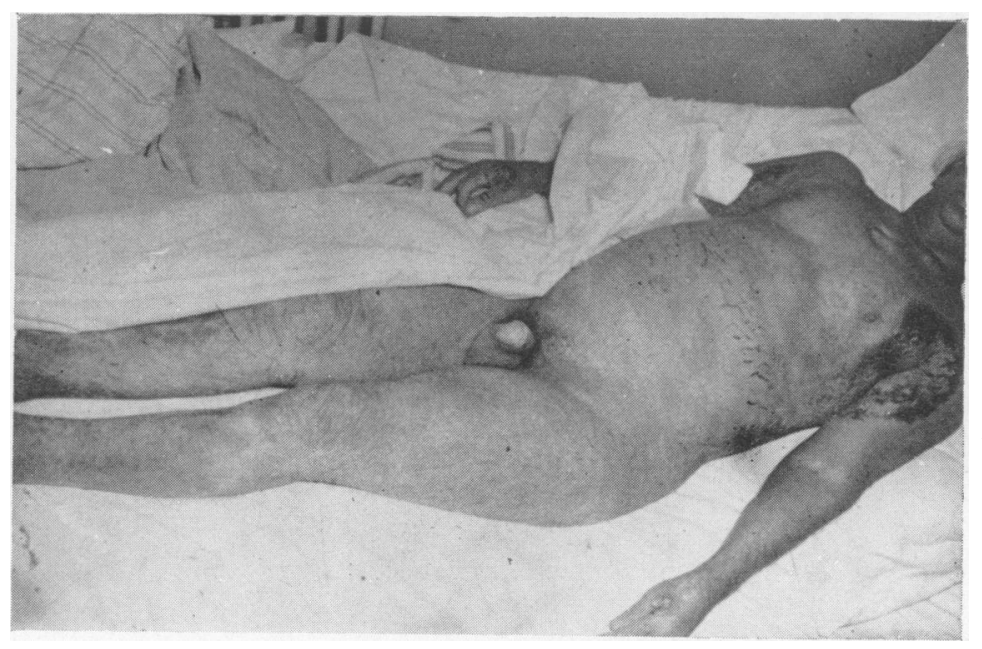

FIG. 1 . 

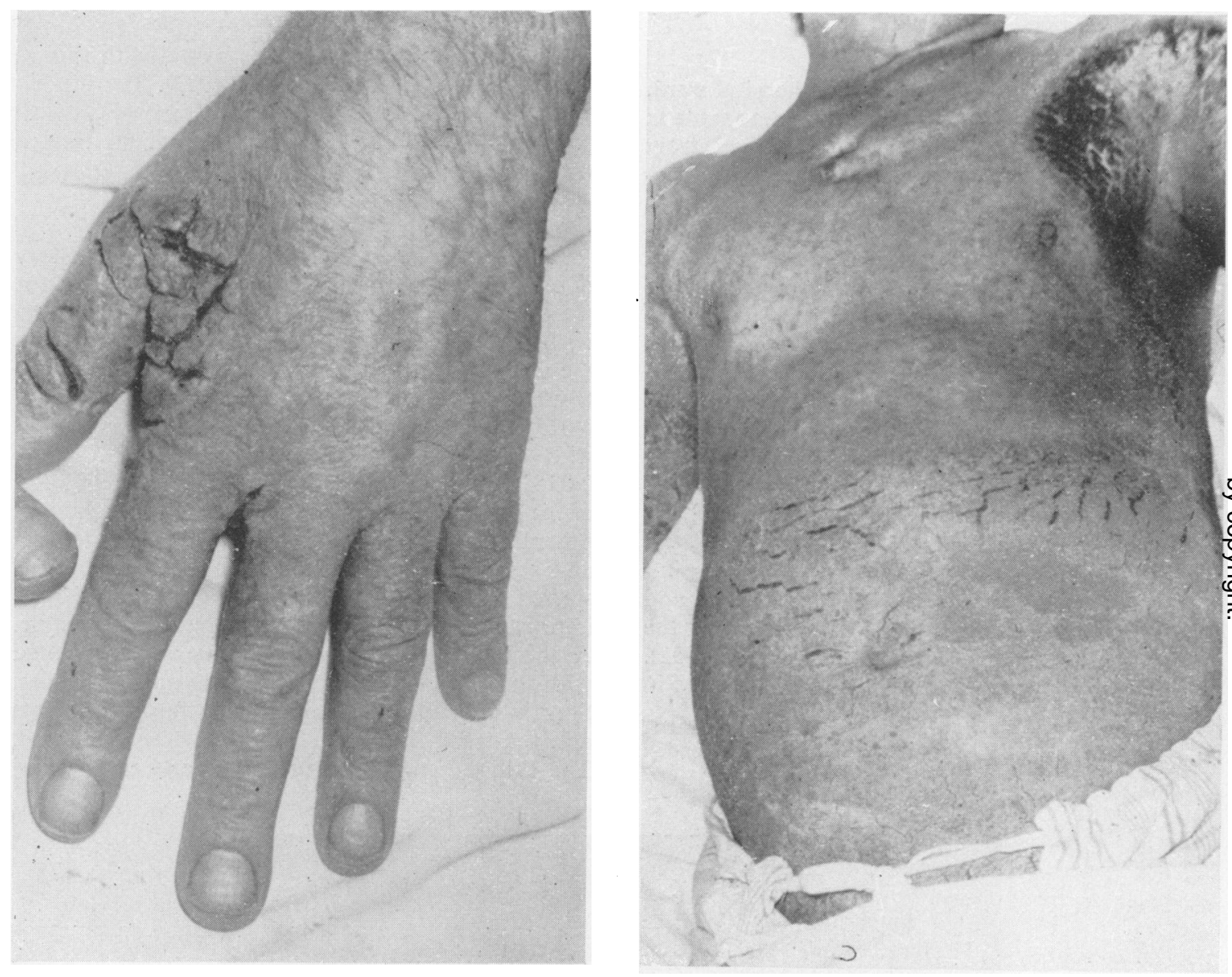

FIG. 2.

Fig. 3. e. O 


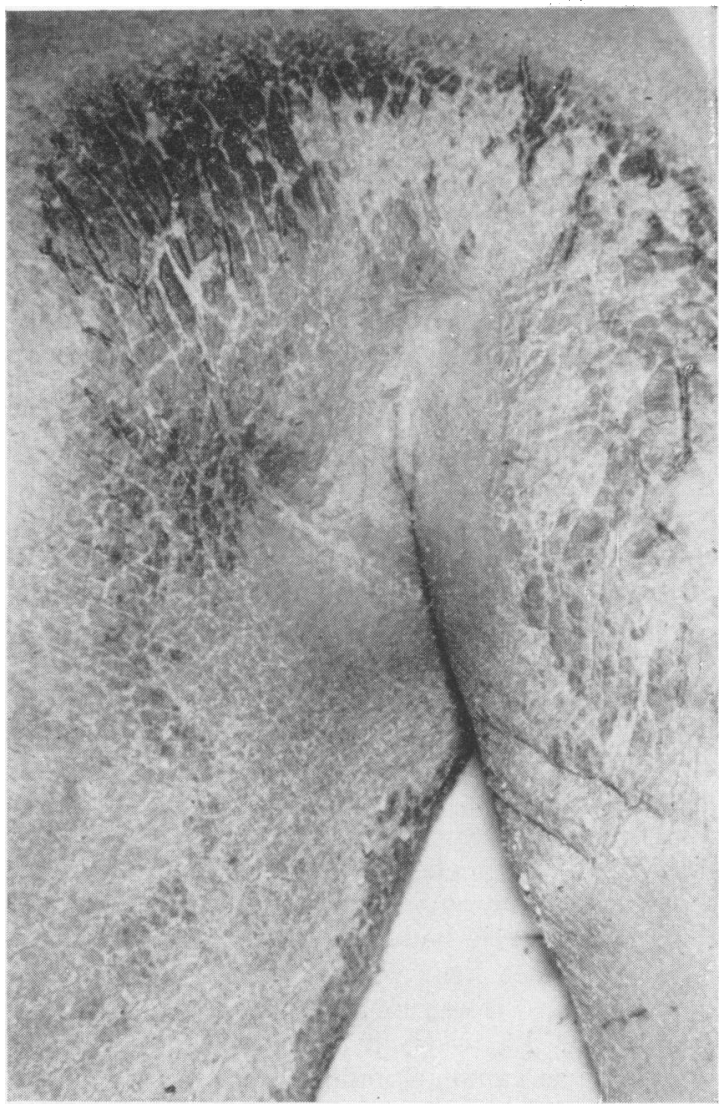

FIG. 4.

were seen in his scales under the microscope. He was treated with four applications of gamma benzene hexachloride and his skin and mood quickly returned towards normal. All the patients, resident medical and nursing staff of the ward were similarly treated. Subsequently scabies was clinically diagnosed and successfully treated in the two flatmates of one of the nurses, six other nurses, a visitor to the patient, several of his family who visited, three patients attending out-patients who had been discharged before the mass anti-scabetic treatment, one of the ward consultants and his wife and the authors -a total of about thirty cases.

\section{Discussion}

The onset of itching in scabies is thought to be due $\stackrel{\mathbb{D}}{\varrho}$ to hypersensitivity to acarine antigen. The immune $c$. response is cell-mediated, probably with some skin $\overrightarrow{\vec{c}}$ IgE (Burgess, 1973). Indeed, with reinfection, itching starts at once (Mellanby, 1972). Failure of removal of acari by scratching is thought to be a major factor $\overline{\frac{\sigma}{\sigma}}$ in the development of Norwegian scabies (Mellanby, $\overline{\mathbb{d}}$ 1972) hence its occurrence in mental defectives with $\varrho$ or without sensory dysfunction, and debilitated is patients with malnutrition and systemic disease. It $\overrightarrow{0}$ has been postulated that immunosuppressant therapy $\vec{\overrightarrow{ }}$ may inhibit the primary immune response (Paterson $\vec{\omega}$ et al., 1973). The occurrence of Norwegian scabies $\frac{}{0}$ in patients with lymphoma and leukaemia may be $\frac{0}{3}$ the result of defective immune mechanisms. Topical of steroids suppress cell mediated immunity in the skin (Weston et al., 1972), hence the lack of papular 6 reaction and itching.

\section{Acknowledgments}

We thank Dr M. Feiwel, Dermatologist, St Charles' Hospital, London W.10, for permission to publish this case.

\section{References}

BURGESS, I. (1973) Unusual features of scabies associated with topical fluorinated steroids. British Journal of De matology, 88, 519.

Calnan, C.D. (1950) Crusted scabies. British Journal Dermatology, 62, 71.

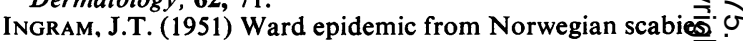
British Journal of Dermatology, 63, 311.

LogaN, J.C.P., GRANT, P.W. \& KeCzKes, K. (1967) Norwegian scabies and lymphatic leukaemia. British Journal of Dermatology, 79, 303.

Macmillan, A.L. (1972) Unusual features of scabies associated with topical fluorinated steroids. British Journal of Dermatology, 87, 496.

Maguire, H.C. \& Kligman, A.M. (1960) Norwegian scabies. Archives of Dermatology, 82, 62.

Mellanby, K. (1972) Scabies, 2nd edn. E. W. Classey Limited, Faringdon, Berks.

Paterson, W.D., Allen, B.R. \& Beveridge, G.W. (1973) Norwegian scabies during immunosuppressive therapy. British Medical Journal, 4, 211.

WALSHE, M.M. (1967) Norwegian scabies. West Indian Medical Journal, XVI, 57.

Wells, G.C. (1952) Norwegian scabies. British Medical Journal, 2, 18.

Weston, W.L., Mandel, M.J., Krueger, C.G. \& Claman, H.N. (1972) Differential suppressive effect of hydrocor- 윽 tisone on lymphocytes and mononuclear macrophages in delayed hypersensitivity of guinea-pigs. Journal of In- $\frac{7}{0}$ vestigative Dermatology, 59, 345.

Zoon, J.J. \& MALI, J.W.H. (1949) Scabies crustosa s. N norvegica. Acta dermatolo-venereologica, Stockholm, 29, $\Omega$ 179. 